\title{
Neurological injury as a complication of spinal surgery: incidence, risk factors, and prognosis
}

\author{
L. M. Romero-Muñoz ${ }^{1}$ A. Segura-Fragoso ${ }^{2} \cdot$ F. Talavera-Díaz ${ }^{3} \cdot$ J. Guimbard-Pérez $^{4} \cdot$ D. Caba-Mora ${ }^{5}$. \\ A. Barriga-Martín ${ }^{1,6}$
}

Received: 5 July 2019 / Revised: 16 September 2019 / Accepted: 24 September 2019 / Published online: 16 October 2019

(c) The Author(s), under exclusive licence to International Spinal Cord Society 2019

\begin{abstract}
Study design Retrospective cohort study.

Objective To assess the rate, injury site, aetiology and outcomes in elective spinal surgery patients who sustained a spinal cord injury (SCI).

Setting SCI national centre Toledo, Spain.

Methods The study sample included patients who sustained an SCI after elective spinal surgery from 2013 to 2017. Oncological patients and patients receiving interventional therapies were excluded. Data collected included: demographics, aetiology, precipitating cause, injury mechanism, injury site, neurological status (AIS), SCIMIII at admission and discharge, hypertension, diabetes mellitus, obesity, dyslipidemia, depression and hospital length of stay.

Results One thousand two hundred and eighty-two patients were admitted in this period of whom 114 met the inclusion criteria with a median (IQR) age of 58 (45-69) years; 46\% female. The prevalence of SCI as a complication following spinal surgery in the total number of patients admitted to our centre was $9 \%$. In $43 \%$, the injury was to the dorsal spine with $\mathrm{T} 12$ being the most common neurological level of injury (20\% of cases following laminectomy secondary to spinal canal stenosis). The most frequent precipitating cause was epidural haematoma (38\% of cases). The median (IQR) SCIMIII scores at admission and discharge were (31) points (20-54) and (67) points (34-81), respectively. General AIS at admission were C (35\%) and $\mathrm{D}$ at discharge (54\%). The presence of hypertension, diabetes mellitus, obesity and dyslipidemia adjusted by age was not linked to a higher complication rate. The median (IQR) hospital length of stay was 120 days (60-189).
\end{abstract}

Conclusion In total $8.9 \%$ of patients admitted with SCI were the result of elective spinal surgery.

L. M. Romero-Muñoz

luismadoc@gmail.com

1 Department of Orthopaedic Surgery, Hospital Nacional de Parapléjicos, Toledo, Spain

2 Research deparment, Instituto de Ciencias de la Salud, Talavera de la Reina, Toledo, Spain

3 Department of Medical Rehabilitation, Hospital Nacional de Parapléjicos, Toledo, Spain

4 Department of Orthopaedic Surgery, Sanatorio Allende, Córdoba, Argentina

5 Department of Orthopaedic Surgery, Hospital Las Higueras, Concepción, Chile

6 School of Medicine, University of Castilla-La Mancha, Toledo, Spain

\section{Introduction}

Spinal cord injury (SCI) following elective surgery has a high social, financial and personal cost for the patient, surgeon and institution involved, with significant legal repercussions. The estimated incidence is between 12 and 57 cases per million population, with incidences fluctuating by around $15 \%$ complication rate depending on the series evaluated [1, 2]. Mechanisms of SCI during surgery include: (1) direct contusion; (2) compression secondary to epidural haematoma in the postoperative period; (3) spinal cord ischaemia during deformity reduction and correction manoeuvres or due to hypotension during surgery; or (4) a combination of the above [3].

Despite the devastating nature of this complication, few studies reflect the long-term prognosis of these patients or provide data to better inform patients considering spinal surgery of the consequences [1-5]. 
The aim of this study is to analyse, at a leading national centre for the comprehensive treatment of patients with SCI the prevalence, site of injury, aetiology, associated risk factors and progression of neurological and functional status of patients affected by SCI as a complication following elective spinal surgery over a 5-year period.

\section{Methods}

\section{Study design}

This is an observational, analytical, longitudinal and retrospective cohort study. The study evaluated 1282 patients with SCI of different aetiologies, admitted to a dedicated hospital specialising in the comprehensive treatment of SCI, from 1 January 2013 to 1 March 2017. The institution has a catchment of 15 million people and in addition serves as a tertiary referral centre for complex SCI throughout all of Spain.

The study's inclusion criteria were as follows: (1) patients undergoing elective surgery for a spinal pathology at other national centres, referred to our centre for comprehensive treatment of their SCI; (2) presentation of an acute SCI in the immediate postoperative period following surgery; (3) absence of SCI prior to elective surgery; (4) referred in the period from 2013 to 2017. The exclusion criteria were: (1) SCI following primary or metastatic cancer surgery; (2) SCI secondary to diagnostic procedures, epidural puncture or procedures performed during childbirth. Of note, patients with myelopathies prior to the surgical procedure were not excluded.

The data collected for the analysis were: demographic variables (age, sex), aetiology of the SCI, precipitating procedure, neurological level of injury (NLI), progression of neurological status according to the American Spinal Injury Association (ASIA) Impairment Scale (AIS) for SCI, functional capacity at admission and discharge as measured by the Spinal Cord Independence Measure (SCIMIII) scale (validated in Spanish), hypertension, diabetes mellitus, obesity, dyslipidaemia and depression.

\section{Statistical analysis}

\section{Univariate analysis}

The following dichotomous variables were coded: sex (1: female; 2 : male), presence of: hypertension (1: yes; $2:$ no), diabetes mellitus (1: yes; 2: no), obesity (1: yes; 2: no), dyslipidaemia (1: yes; 2 : no), depression (1: yes; 2 : no).

The continuous quantitative variables evaluated were age and SCIMIII, and the ordinal categorical variables were AIS scale.
Categorical variables were represented with absolute frequencies and percentages. Continuous variables were represented with median and interquartile range (IQR).

\section{Multivariable analysis: risk factors}

To determine the variables associated with complications from the surgery, age-adjusted odds ratios were calculated using logistic regression models with the dependent variable of surgical complications and the independent variables of diabetes, obesity, hypertension, dyslipidaemia and depression. The data obtained were entered into an Excel database (Microsoft Office for Windows Vista). Statistical analysis were carried out using IBM SPSS Statistics 22 for health sciences (SPSS Inc., Chicago, IL, US). Values of $p<0.05$ were considered to be statistically significant.

\section{Results}

Of the total of 1282 patients admitted with SCI during the study period, 114 patients $(8.9 \%)$ had experienced an SCI following elective spinal surgery. This corresponded to 62 men and 52 women with a median (IQR) age of 58 years (45 to 69 ).

The median (IQR) SCIMIII score was 31 (20 to 54) points at admission and 67 (34 to 81 ) points at discharge. Median (IQR) hospital stay was 120 days (60-189).

The minimum follow-up period was 1 year, with a median (IQR) follow-up of 2.5 years (1-4) years. The SCI was located in the cervical spine in 34 patients $(30 \%)$, in the dorsal spine in 49 patients $(43 \%)$ and in the lumbar spine in 31 patients $(27 \%)$. The main indication for surgery was pain and radiculopathy without deficit in the cervical and lumbar spine (Fig. 1).

In the cervical area (34 patients) (Table 1), C4NLI was the most common (11 patients) followed by C6 NLI (7 patients). The median (IQR) SCIMIII score in the cervical area was 20 points (15-37) at admission and 37 points (19-79) at discharge. Median (IQR) hospital stay was 123 days (102-204).

The precipitating surgical procedure was discectomy and arthrodesis in 12 patients (35\%), and corporectomy and arthrodesis in 6 patients (18\%). The precipitating cause was the presence of myelopathy prior to the surgical procedure $(40 \%)$, formation of an epidural haematoma in the immediate postoperative period $(35 \%)$ and intraoperative spinal cord contusion (15\%). Progression in the AIS scale is shown in Fig. 2a.

In the dorsal spine (49 patients) (Table 2), T12NLI was the most commonly affected area (10 patients). The median (IQR) SCIMIII score was 31 points (23-41) at admission and 67 points (43-77) at discharge. Median (IQR) hospital stay was 133 days (60-190). The surgical procedure precipitating the SCI was decompressive laminectomy 
Fig. 1 Distribution of surgical procedure leading to spinal cord injury

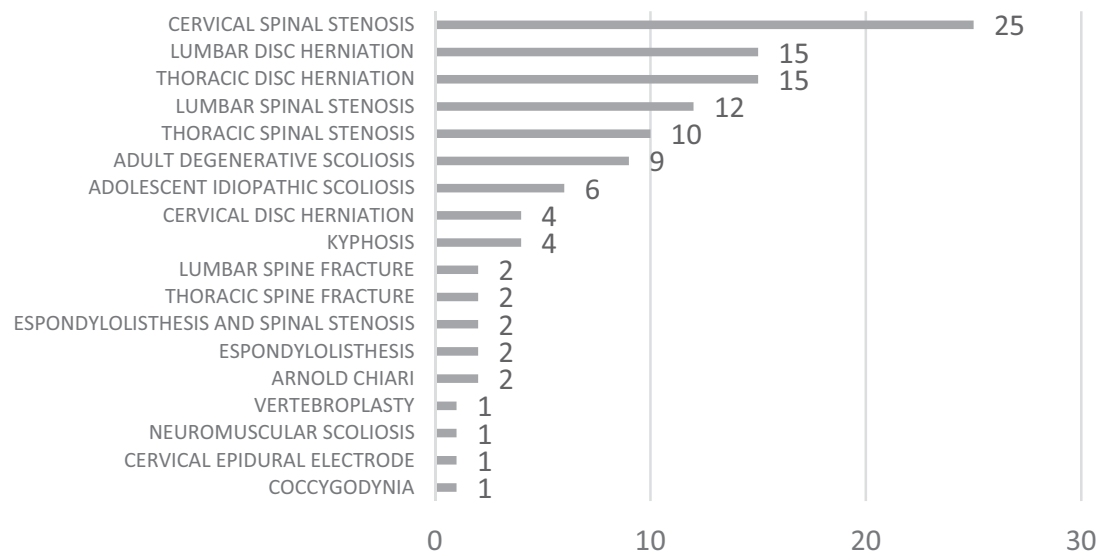

combined with discectomy or discectomy alone in 29 patients $(59 \%)$. The underlying aetiology was adult degenerative scoliosis in $9 / 49(18 \%)$ and adolescent idiopathic scoliosis in 6/49 (12\%). All of these patients underwent intraoperative neuromonitoring.

Precipitating causes were the formation of an epidural haematoma in the immediate postoperative period $(37 \%)$, intraoperative spinal cord contusion $(16 \%)$ and spinal cord ischaemia (14\%). Progression in the AIS scale is shown in Fig. 2b.

In the lumbar area (31 patients) (Table 3), 14 patients experienced cauda equina syndrome without a specific neurological level, and metamere L1 was the neurological level in 6 patients $(19 \%)$. The median SCIMIII score was 54 points (32-65) at admission and 81 points (65-86) at discharge. Median (IQR) hospital stay was 90 days (37-152). The precipitating surgical procedure was laminectomy and discectomy in ten patients $(32 \%)$, and laminectomy and arthrodesis in six patients (19\%). The precipitating cause was epidural haematoma in the immediate postoperative period (55\%), and cauda equina syndrome without specific cause (9\%). Progression in the AIS scale is shown in Fig. 2c.

Following discharge patients were reviewed on an annual basis.

Of the risk factors studied, no statistically significant differences were found between the groups regarding age, diabetes mellitus, obesity, hypertension or depression (Table 4). Dyslipidaemia, however, showed statistically significant differences $(p=0.04)$. OR $0.34 \quad(95 \%$ CI $0.12-0.96) p=0.043$.

One patient with SCI following cervical spinal stenosis surgery died due to the complications.

\section{Discussion}

Knowledge of the possible risk factors of iatrogenic injury following elective spinal surgery is of major interest for
Table 1 Description of the cervical lesions

\begin{tabular}{|c|c|c|c|}
\hline & & Count & $\%$ \\
\hline \multirow[t]{3}{*}{ Sex } & Male & 20 & $58.8 \%$ \\
\hline & Female & 14 & $41.2 \%$ \\
\hline & Total & 34 & $100.0 \%$ \\
\hline \multirow{8}{*}{$\begin{array}{l}\text { Neurological level of } \\
\text { injury (NLI) }\end{array}$} & $\mathrm{C} 1$ & 1 & $2.9 \%$ \\
\hline & $\mathrm{C} 2$ & 2 & $5.9 \%$ \\
\hline & $\mathrm{C} 3$ & 4 & $11.8 \%$ \\
\hline & $\mathrm{C} 4$ & 11 & $32.4 \%$ \\
\hline & $\mathrm{C} 5$ & 5 & $14.7 \%$ \\
\hline & C6 & 7 & $20.6 \%$ \\
\hline & $\mathrm{C} 7$ & 2 & $5.9 \%$ \\
\hline & $\mathrm{C} 8$ & 1 & $2.9 \%$ \\
\hline \multirow[t]{7}{*}{ Precipitating cause } & Upper level fracture & 1 & $2.9 \%$ \\
\hline & Epidural haematoma & 12 & $35.3 \%$ \\
\hline & Subdural haematoma & 1 & $2.9 \%$ \\
\hline & $\begin{array}{l}\text { Manipulation/spinal } \\
\text { cord contusion }\end{array}$ & 5 & $14.7 \%$ \\
\hline & $\begin{array}{l}\text { Spinal cord } \\
\text { manipulation/ } \\
\text { dural lesion }\end{array}$ & 1 & $2.9 \%$ \\
\hline & $\begin{array}{l}\text { Spinal cord } \\
\text { manipulation/prior } \\
\text { myelopathy }\end{array}$ & 13 & $38.2 \%$ \\
\hline & $\begin{array}{l}\text { Interbody cage } \\
\text { migration }\end{array}$ & 1 & $2.9 \%$ \\
\hline
\end{tabular}

patients, relatives and professionals. Understanding the prognosis and course of such injuries would be of great benefit.

In the study time period, $8.9 \%$ of cases of SCI were secondary to elective spinal surgery. A similar proportion has been reported in the literature [1-3]. However, there are few studies in the literature on SCI occurring exclusively during a surgical procedure [1-8].

Cramer et al. report a $0.3 \%$ incidence of SCI following spinal surgery, after reviewing a series of 11,817 patients 

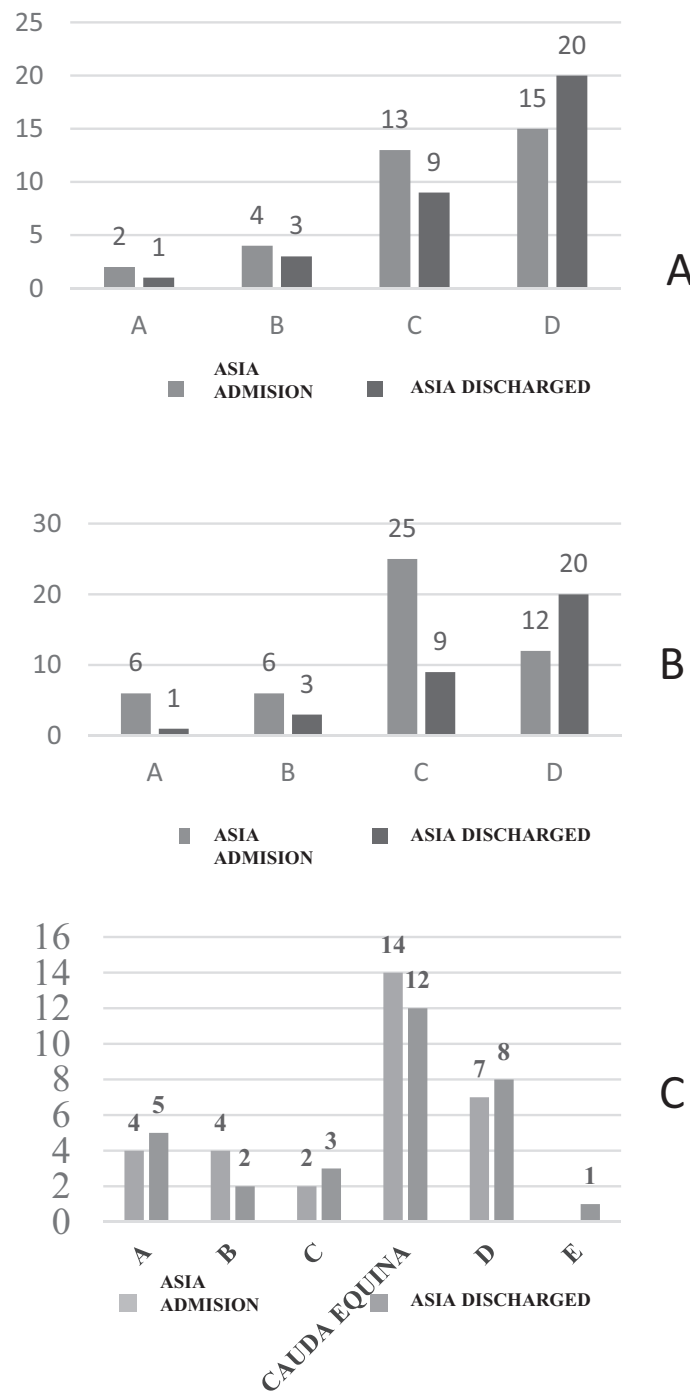

Fig. 2 a Cervical neurological status evaluated using the American Spinal Injury Association Impairment Scale (AIS) at the time of admission/discharge. b Thoracic neurological status evaluated using the American Spinal Injury Association Impairment Scale (AIS) at the time of admission/discharge. c Lumbar neurological status evaluated using the American Spinal Injury Association Impairment Scale (AIS) at the time of admission/discharge

having undergone surgery at the same institution. SCI occurred in only 11 cases [9].

As was the case with our series, several studies reveal the dorsal region to be the most commonly affected location $[7,8]$. This is due to the fact that the spinal cord is more prone to injury in this location when attempting to move it to access the disc or vertebral body. This explains why our series observed that around $50 \%$ of patients having undergone dorsal laminectomy experienced an SCI. It is important for surgeons to recognise that any decompression of dorsal spinal canal may lead to venous bleeding from epidural venous plexus in this area. Close clinical observation and early postoperative imaging in suspected cases are
Table 2 Descriptions of the dorsal lesions

\begin{tabular}{|c|c|c|c|}
\hline & & Count & $\%$ \\
\hline \multirow[t]{3}{*}{ Sex } & Male & 25 & $51.0 \%$ \\
\hline & Female & 24 & $49.0 \%$ \\
\hline & Total & 49 & $100.0 \%$ \\
\hline \multirow{12}{*}{$\begin{array}{l}\text { Neurological level of } \\
\text { injury (NLI) }\end{array}$} & $\mathrm{T} 1$ & 1 & $2.0 \%$ \\
\hline & $\mathrm{T} 10$ & 5 & $10.2 \%$ \\
\hline & $\mathrm{T} 11$ & 6 & $12.2 \%$ \\
\hline & $\mathrm{T} 12$ & 10 & $20.4 \%$ \\
\hline & $\mathrm{T} 2$ & 2 & $4.1 \%$ \\
\hline & $\mathrm{T} 3$ & 6 & $12.2 \%$ \\
\hline & $\mathrm{T} 4$ & 6 & $12.2 \%$ \\
\hline & $\mathrm{T} 5$ & 3 & $6.1 \%$ \\
\hline & T6 & 4 & $8.2 \%$ \\
\hline & $\mathrm{T} 7$ & 2 & $4.1 \%$ \\
\hline & $\mathrm{T} 8$ & 2 & $4.1 \%$ \\
\hline & $\mathrm{T} 9$ & 2 & $4.1 \%$ \\
\hline \multirow[t]{11}{*}{ Precipitating cause } & $\begin{array}{l}\text { Surgical management } \\
\text { of tethered spinal cord }\end{array}$ & 1 & $2.0 \%$ \\
\hline & Epidural haematoma & 18 & $36.7 \%$ \\
\hline & Subdural haematoma & 1 & $2.0 \%$ \\
\hline & $\begin{array}{l}\text { Medial implantation } \\
\text { pedicle screw }\end{array}$ & 1 & $2.0 \%$ \\
\hline & Spinal ischaemia & 7 & $14.3 \%$ \\
\hline & $\begin{array}{l}\text { Manipulation/spinal } \\
\text { cord contusion }\end{array}$ & 8 & $16.3 \%$ \\
\hline & $\begin{array}{l}\text { Spinal cord } \\
\text { manipulation/calcified } \\
\text { herniated disc }\end{array}$ & 2 & $4.1 \%$ \\
\hline & $\begin{array}{l}\text { Spnal cord } \\
\text { manipulation/ } \\
\text { dural lesion }\end{array}$ & 2 & $4.1 \%$ \\
\hline & $\begin{array}{l}\text { Spnal cord } \\
\text { manipulation/prior } \\
\text { myelopathy }\end{array}$ & 7 & $14.3 \%$ \\
\hline & $\begin{array}{l}\text { Posterior longitudinal } \\
\text { ligament ossification }\end{array}$ & 1 & $2.0 \%$ \\
\hline & Ponte osteotomy & 1 & $2.0 \%$ \\
\hline
\end{tabular}

mandatory in order to prevent permanent morbidity. Iatrogenic SCI following elective cervical surgery has very low incidences, as shown by Lee et al., with levels reaching $0.1 \%$ [10]. In the lumbar area, the incidence of neurological complications reported was $9 \%$ [9].

In the cervical area, we observed a higher incidence of injuries using an anterior approach compared with the posterior approach. This finding may be due to the fact that, in Spain, a higher percentage of anterior approaches are performed than posterior approaches.

The presence of prior myelopathy is a risk factor for SCI, due to the greater susceptibility of a spinal cord with chronic abnormalities. Spinal cord functions have started to 
Table 3 Description of the lumbar lesions

\begin{tabular}{|c|c|c|c|}
\hline & & Count & $\%$ \\
\hline \multirow[t]{3}{*}{ Sex } & Male & 17 & $54.8 \%$ \\
\hline & Female & 14 & $45.2 \%$ \\
\hline & Total & 31 & $100.0 \%$ \\
\hline \multirow[t]{2}{*}{ Localization } & Lumbar & 30 & $96.8 \%$ \\
\hline & Sacrum & 1 & $3.2 \%$ \\
\hline \multirow{6}{*}{$\begin{array}{l}\text { Neurological level of } \\
\text { injury (NLI) }\end{array}$} & Cauda equina & 14 & $45.2 \%$ \\
\hline & L1 & 6 & $19.4 \%$ \\
\hline & L3 & 4 & $12.9 \%$ \\
\hline & L4 & 5 & $16.1 \%$ \\
\hline & L5 & 1 & $3.2 \%$ \\
\hline & $\mathrm{S} 2$ & 1 & $3.2 \%$ \\
\hline \multirow[t]{7}{*}{ Precipitating cause } & Cauda equina & 9 & $29.0 \%$ \\
\hline & Epidural haematoma & 17 & $54.8 \%$ \\
\hline & $\begin{array}{l}\text { Haematoma subdural/ } \\
\text { dural fistula }\end{array}$ & 1 & $3.2 \%$ \\
\hline & $\begin{array}{l}\text { Manipulation/spinal cord } \\
\text { contusion }\end{array}$ & 1 & $3.2 \%$ \\
\hline & Prior myelomeningocele & 1 & $3.2 \%$ \\
\hline & $\begin{array}{l}\text { Posterior longitudinal } \\
\text { ligament ossification }\end{array}$ & 1 & $3.2 \%$ \\
\hline & Conversion disorder & 1 & $3.2 \%$ \\
\hline \multirow[t]{5}{*}{ Asia at admission } & A & 4 & $12.9 \%$ \\
\hline & B & 4 & $12.9 \%$ \\
\hline & $\mathrm{C}$ & 2 & $6.5 \%$ \\
\hline & Cauda equina & 14 & $45.2 \%$ \\
\hline & D & 7 & $22.6 \%$ \\
\hline
\end{tabular}

deteriorate before surgery already. This fact must be taken into account when managing these patients and they should be advised of this risk [10].

While other studies have associated age as a risk factor for SCI due to the reduced capacity for recovery of neurons and the degeneration of anatomical structures [10-12], our series did not find a higher incidence in older patients.

Sex did not show any significant differences either, in contrast to other studies that reflect this $[11,12]$. These studies show the neuroprotective effect of oestrogen and progesterone in women $[13,14]$. Our study also did not find a statistically significant relation between diabetes mellitus, obesity, hypertension or depression and the risk of suffering from iatrogenic injury. We did, however, find differences in relation to dyslipidaemia. While these differences are statistically significant, we do not consider them to be clinically relevant. Although comorbidities did not reach statistical significance, our practice is to ensure that they are well controlled prior to elective surgery.

In relation to the possible causes of the iatrogenic SCI, two clinical entities have been differentiated: epidural haematoma and spinal cord ischaemia. The results of this study
Table 4 Multivariable analysis. Risk factors of developing SCI following spine surgery. Odds ratio and $P$ values

\begin{tabular}{|c|c|c|c|c|}
\hline & \multirow[t]{2}{*}{ Odds ratio } & \multicolumn{2}{|l|}{$95 \% \mathrm{CI}$} & \multirow[t]{2}{*}{$P$ value } \\
\hline & & Inferior & Superior & \\
\hline Age & 1.004 & 0.977 & 1.033 & 0.759 \\
\hline $\begin{array}{l}\text { Diabetes mellitus } \\
\text { yes vs. no }\end{array}$ & 0.695 & 0.203 & 2.376 & 0.562 \\
\hline Obesity yes vs. no & 0.517 & 0.158 & 1.692 & 0.276 \\
\hline Hypertension yes vs. no & 1.469 & 0.559 & 3.864 & 0.436 \\
\hline Dyslipidaemia yes vs. no & 0.480 & 0.157 & 1.466 & 0.197 \\
\hline Depression yes vs. no & 2.691 & 0.953 & 7.594 & 0.061 \\
\hline
\end{tabular}

show epidural haematoma to be the cause of $42 \%$ of SCI cases. However, epidural haematoma has been observed in MRI studies in $33 \%$ of cases following decompression/ herniated disc surgery, the majority of which are asymptomatic. According to Sokolowski et al., only $0.1-0.2 \%$ of cases require surgical evacuation [15]. Massimo et al. reported that epidural haematomas measuring under $75 \mathrm{~mm}^{2}$ within the dural sac are clinically asymptomatic [16].

A study prepared by Bacher revealed that $43 \%$ of patients with SCI following spinal surgery are related to surgical procedures near the spinal cord, and the other 57\% are of ischaemic aetiology or toxic mechanisms [17].

This study demonstrates that increased risk of developing SCI relates to: cervical stenosis with prior myelopathy (25 cases), thoracic disc herniation (15 cases) and lumbar spinal stenosis (15 cases). Similar to our study, Bacher et al., describes six patients with SCI following spinal surgery due to decompressive intervention [17]. Unlike traumatic SCI, most patients improve from the neurological perspective both in terms of the AIS scale and the SCIM III scale, in all spinal cord areas.

There are no protocols in the reviewed literature which guarantee the prevention of SCI after elective spinal surgery, regarding its optimal management [18].

In terms of time frames, we observed similar data to that found in studies such as that by Kim et al.; $29 \%$ occurred intraoperatively, $61 \%$ were recognised in the perioperative period and $11 \%$ in the postoperative period [19].

The study's limitations are those inherent to a retrospective study on patients from different centres. It is not possible to calculate the actual incidence of neurological injury associated with spinal surgery, as only the most complex patients who cannot be treated at their hospital of origin are admitted to our centre. There is also no way for us to know if the medical records reflect exactly what happened in the operating room, as there is a medical/legal implication and pursuit of possible compensation in all these cases. As such, we will never know the actual cause of the injuries, although epidural haematoma appears to be the most common cause. 
Complications during the immediate postoperative period of 24-48 h after surgery have not been mapped in this study. The variables collected in the study were the variables we consider with clinical relevance and possible confounders.

Nevertheless, one of the study's strengths is that the results obtained can be transferable and representative of a population. Similarly, the results of this study can be useful for clinics, patients and future studies aimed at understanding the prognosis and course of this serious injury.

\section{Conclusion}

Of all patients admitted with SCI in our reference area during the study period, $8.9 \%$ were due to elective spinal surgery. The posterior approach in the dorsal spine was the most common site. In general, there is neurological recovery, albeit incomplete. The median hospital stay at an SCI rehabilitation centre was 120 days (IQR 60-189), with the financial and social repercussions such a stay entails.

More prospective studies are required with the aim of establishing the actual incidence, the risk factors and to try to reduce this serious complication as far as possible in patients undergoing spinal surgery.

\section{Data availability}

The datasets generated and/or analysed during the currents study are available from the corresponding author on reasonable request.

Acknowledgements We thank Dr Geoffrey Tipper for reviewing the paper and english translation. This study was presented in Spanish National Spine Congress GEER 2018.

Funding This work was not funded by any universities, charities and commercial organisations, as well as sources of any study materials.

Author contributions LMR: conception and design of the study, analysing and interpreting data, drafting and revising the paper and approval of the final version of the paper. AS, FT, DC, AB: conception and design of the study, analysing and interpreting data, revising the paper and approval of the final version of the paper. JG: Contributed to data extraction. All authors of this paper meet the requirements of the guidelines for ethical authorship and publishing as stated in Spinal Cord.

\section{Compliance with ethical standards}

Conflict of interest The authors declare that they have no conflict of interest.

Ethical approval We certify that all applicable institutional and governmental regulations concerning the ethical use of human volunteers were followed during the course of this research.
Publisher's note Springer Nature remains neutral with regard to jurisdictional claims in published maps and institutional affiliations.

\section{References}

1. Montalva-Iborra A, Alcanyis M, Grao C. Risk factors in iatrogenic spinal cord injury. Spinal Cord. 2017;55:818-22.

2. Alcanyis-Alberola M, Giner-Pascual $M$. Iatrogenic spinal cord injury: an observational study. Spinal Cord. 2011;49: 1188-92.

3. Bridwell KH, Lenke L, Baldus C. Major intraoperative neurologic deficits in pediatric and adult spinal deformity patients. Incidence and etiology at one institution. Spine. 1998;23:324-31.

4. Æsøy MS, Solvang SH, Grønning M, et al. of persistent iatrogenic spinal cord injuries in western norway. Brain Behav. 2016;6:1-5.

5. O'Connor RJ, Murray PC. Review of spinal cord injuries in Ireland. Spinal Cord. 2006;44:445-8.

6. Flynn TB. Neurologic complications anterior cervical interbody fusion. Spine. 1982;7:536-9.

7. Chen Qi, Li Feng, Wu Wei. Risk factors of latrogenic spinal cord injury in spinal surgery: a multicenter retrospective study. IntJ Neurosci. 2012;122:606-10.

8. Daniels A, Hart A, Hilibrand A. Iatrogenic spinal cord injury resulting from cervical spine surgery. Glob Spine J. 2017;7:84-90.

9. Cramer DE, Maher PC, Pettigrew DB. Major neurologic deficit after adult spinal surgery: Incidence and etiology over 10 years at a single training institution. J Spinal Disord Tech. 2009;22: 565-70.

10. Lee JY, Hilibrand AS, Lim MR. Characterization of neurophysiologic alerts during anterior cervical spine surgery. Spine. 2006;31:1916-22.

11. Su A, Habermann E, Thomsen K, et al. Risk factors for 30-day unplanned readmission and major perioperative complications following spine fusion surgery in adults: a review of the national surgical quality improvement program (NSQIP) database. Spine. 2016;41:1523-34.

12. Vitale MG, Moore DW, Matsumoto $\mathrm{H}$, et al. Risk factors for spinal cord injury during surgery for spinal deformity. J Bone $\mathrm{Jt}$ Surg Am. 2010;92:64-71.

13. Nakamura M, Raghupathi R, Merry DE, et al. Overexpression of $\mathrm{Bcl}-2$ is neuroprotective after experimental brain injury in transgenic mice. J Comp Neurol. 1999;412:681-92.

14. Yune TY, Park HG, Lee JY, et al. Estrogen-induced Bcl-2 expression after spinal cord injury is mediated through phosphoinositide-3-kinase/Akt-dependent CREB activation. J Neurotrauma. 2008;25:121-31.

15. Sokolowski MJ, Garvey TA, Perl J. Prospective study of postoperative lumbar epidural hematoma: incidence and risk factors. Spine. 2008;33:108-13.

16. Massimo A, Leonardi M. Zanetti. Early postoperative MRI in detecting hematoma and dural compression after lumbar spinal decompression: prospective study of asymptomatic patients in comparison to patients requiring surgical revision. Eur Spine J. 2010;19:2216-22.

17. Bacher T, Schiltenwolf M, Niethard FU, et al. The risk of paraplegia through medical treatment. Spinal Cord. 1999;37:172-82.

18. Schairer WW, Carrer A, Deviren V, et al. Hospital readmission after spine fusion for adult spinal deformity. Spine. 2013;38: 1681-9.

19. Kim YH, Ha KY, Kim SI. Spinal cord injury and related clinical trials. Clin Orthop Surg. 2017;9:1-9. 